\title{
Relationship Between Safety Measures and Human Error in the Construction Industry: Working at Heights
}

\author{
Bussier, Mathieu Jonathan Pascal \& Chong, Heap-Yih (John)
}

\begin{abstract}
In recent years, falling from heights (FFH) has been reported as the primary cause of fatalities within the Australian construction industry. While there is substantial literature exploring safety and human error in attempt to decrease the occurrences of accidents through the implementation of organisational and physical hazards related strategies, little attention has been brought towards the impact of psychological distress on the relationship between human error and safety measures. Therefore, this paper is aimed at examining the relationship between safety measures and human error with the objective of identifying the impact of psychological distress among workers working at heights within the construction industry on the relationship. This study found that human error can occur as a result of psychological distress and therefore provides a foundation for future research to explore whether proper implementation of psychological safety measures could decrease the occurrence of human failures and accidents when working at heights.
\end{abstract}

Keywords: safety measures; human error; psychological distress; falls from heights; prevention strategies; psychological safety measures; structural equation modelling, Australia

\section{Introduction}

Every year, thousands of deaths, accidents and disabilities result from occupational accidents within the construction industry. According to the International Labour Organisation, 60,000 fatalities are recorded in this industry worldwide annually, with more than $30 \%$ of deaths occurring as a result of falling from heights (FFH) [1]. Fallrelated injuries are the second most common injury and the primary cause of fatalities in the industry with more than 29 deaths recorded every year in Australia [2]. Given these statistics, ensuring the safety of workers on sites has become a priority for the construction industry leaders and researchers who have worked together to develop new 
strategies that minimise the risks hence ensuring the health and safety of workers when working at heights. According to various researchers, in order to guarantee the success of accident prevention strategies, it is crucial to understand the factors that play a key role in causing them [3]. Despite the implementation of new technologies, standards and strategies, the root cause of accidents is attributable to unsafe behaviours and human error [4]. This is evident by the fact that an average of $23 \%$ of falls are associated with labours choosing not to wear any personal protective equipment (PPE), suggesting that workers' behaviours and attitudes towards safety measures play a major role in accident causation [5].

Recent safety studies have focused their attention on different strategies to decrease human error occurrences and improve safety on site, such as the implementation of a human risk factor management plan [] ] continuous training for experienced and young workers [7]; effective use of fall protection systems [ㅁ] and supervisors' commitment towards safe behaviours [9]. Some researchers have also investigated the inclusion of technology as a strategy to detect safety breaches, with the application of the Bluetooth Low Energy (BLE) beacons system allowing supervisors to detect safety violations of workers [10], and the application of Building Information Modelling (BIM) in design allowing potential hazards to be identified at an early stage rather than during the construction phase [11]. Moreover, the government has also worked towards enforcing new safety measures to manage the risk of falls and ensure compliance on sites to reduce the occurrence of falls-related fatalities. The Work Health and Safety (WHS) Act 2011 serves as a backbone for organisations detailing safety measures such as how to effectively manage, eliminate, control and review risks of falls [12]. Additionally, the Act details the appropriate implementation of scaffolds, PPE, barriers, inspections and administrative control to prevent falls [12]. Various studies 
have expanded the understanding of safety and human error. However, while existing research implemented addresses human error and safety in the industry focusing exclusively on organisational and physical hazards, little attention has been brought towards the impact of psychological hazards on human error and safety when working at heights. Extensively explored within the medical and health sector, it was discovered that human error is an interdisciplinary area of psychology, which is impacted by human capability, ergonomics, and workplace safety [13]. With an increasing number of fatalities occurring each year in the construction industry when working at heights, it is imperative to analyse the influence a worker's mental health has on human error and safety measures in order to find the best approaches to eliminate accidents causation when working at heights.

Therefore, the aim of this paper is to analyse the relationship between safety measures and human error with the purpose of reducing the occurrence of human failures when working at heights. The three main objectives to achieve this aim are to (a) identify the factors that impact the psychological state of workers working at heights, (b) identify the interconnection between psychological factors, human error and safety measures and (c) determine the most appropriate approaches to improve safety culture while working at heights. The remainder of this study is structured as follows: Chapter 2 examines previous research and provides a hypothetical model, Chapter 3 presents the research methodology and chosen approach to develop the research, Chapter 4 presents the findings and Chapter 5 discusses the results of study and finally, Chapter 6 provides a conclusion of the study and future directions. 


\section{Theoretical Foundation and Hypotheses Development}

\subsection{Scope of Chapter}

The research examines the current concerns associated with working at heights and the safety measures currently embedded in the construction industry to increase safety. This chapter also provides an overview of human error and outlines how it fits within the industry. This then allows the study to examine the relationship between safety measures and human error in conjunction with psychological distress in order to develop, analyse and test a hypothetical model in the next chapters.

\subsection{Safety Measures when Working at Heights}

Working at heights can be defined as "working in any place where, if precautions were not taken, a person could fall a distance liable to cause personal injury" [14, p.638]. Countless professions involve workers working at heights such as builders, scaffolders, roofers, electricians, plumbers and painters [15]. Recognised as one of the major causes of mortality and serious injury in Australia, 28\% of construction related incidents were related to FFH in 2015 [16]. Fall injuries caused by faulty ladders, as well as falling from roofs and ladders accounted for $30 \%$, and $58 \%$, of FFH related injuries respectively [16]. Due to the severity and frequency of accidents in the construction sector that cause injuries, nearly missed accidents and fatalities, over the past few years, substantial attention and research has been targeted towards improving safety measures [14]. In the late 90's, Gillen et al. [17] first investigated the relationship between injury severity and FFH, outlining the misinterpretation of physical hazards and behaviours in the industry and encouraged researchers to look into education and training, product design, human behaviour, PPE and organisational strategies to reduce fall-related injuries. As a result, various preventative measures and strategies have been developed 
by scholars to improve safety measures and reduce the occurrence of fall-related injuries when working at heights of more than 2 meters.

One of the frequently studied strategies by researchers to improve safety measures when working at heights is the provision of relevant training and development which has proved to lead to a decrease in injury rates [7]. Also considered as an organisational safety measure, "training refers to the acquisition of specific skills or knowledge, and development refers to the improvement of intellectual and emotional ability needed to perform better at a specific job" [18, p.265]. According to Zid et al. [4], organisational factors such as training plays a major role when ensuring safety behaviour in the industry. Therefore, investing in proper safety training and development has helped businesses improve safety measures and increase profitability, productivity and safety culture while helping employees attain the required skills to perform work safely [18].

Another strategy to improve safety is through the implementation of technology. Gomez-de-Gabriel et al. [10] introduced a Bluetooth Low Energy (BLE) beacons system which allows supervisors to detect whether labours are experiencing risky situations by measuring and evaluating the proper use of harnesses when working within delimiting areas that require the use of a harness. Another use of technology aimed at improving safety is the application of BIM during the planning stage to enable the identification and elimination of potential falls hazards that occur in construction schedules which might otherwise be overlooked [19]. Zhang et al. [11], who investigated the use of BIM in safety with two case studies, concluded that implementing existing safety rules and best practices checks, combined with threedimensional designs in the BIM software, allowed the safety team to detect the location 
and severity of potential fall hazards and also recommend the corresponding PPE required to prevent the occurrence of hazards.

Despite the introduction of technology, and collective measures designed to prevent falls from heights, the most common and effective strategy to increase safety measures on site remains the use of fall protection systems []. Considered as the last barrier between the body and the risk factor, numerous scholars have analysed different types of fall protection systems in order to decrease the occurrence of accidents on sites [20]. For instance, Bejinariu et al. [21] analysed the benefits and safety components associated with wearing a harness, while Adam, Pallarés, and Calderón [] $]$ and Brodskiy [20] analysed the benefits of fall arrest nets and concluded that in up to $30 \%$ of cases, fall protection nets remain the only option for safety on site.

Although various strategies and new technologies have been put in place to increase safety at heights, FFH remains the leading cause of construction accidents and fatalities compared to other industries in Australia [14]. Based on data collected over 33 years by the National Safety Council [5], fall-related fatalities represent half of all construction deaths worldwide, with $23 \%$ of fatalities occurring due to workers choosing not to wear their personal fall-arrest devices. According to Kaskutas et al. [22] study, workers reported several occasions where violations occurred when working at heights, including $69 \%$ of participants frequently standing on exterior top plates and walking on elevated floor joints without any PPE. Their study also found that 81 out of the 283 participants did not have sufficient time to work safely due to strict deadlines while 72 participants reported that their supervisor prioritized working faster over safety rules [22]. Similarly, Nadhim et al. [14] and Mohammadi, Tavakolan, and Khosravi [23] established that pressure from both project timelines and supervisors to prioritise productivity over safety impacts workers' attitudes on safety. Furthermore, Kaskutas et 
al. [22] reported that 50\% of participants believed that they could not make suggestions about health and safety, and $45 \%$ of the participants believed that there was no regular communication between the management and employees. Similarly, Hallowell and Yugar-Arias [24] and Korkmaz and Park [25] analysed the impact of communication between employees and management and found that a lack of safety communication can increase human error in the construction industry. Given the aforementioned safety issues that impede safety on sites, it is crucial to better understand and analyse how the psychological state of workers influence the safety measures outlined in Figure 2.1 and in turn lead to human error.

\subsection{Human Error in the Construction Industry}

FFH has long been an issue for the construction industry and yet, investigating the main cause for the occurrence of accidents has still not received a sufficient amount of attention [1]. Zid et al. [4] reported that a large number of FFH fatalities and injuries occur due to human error and unsafe behaviours, calling for scholars to focus their attention on human error theories. According to Mohammadi, Tavakolan, and Khosravi [23], human behaviour and attitude remains one of the most important factors influencing safety in the construction industry. The analysis outlined by Fargnoli and Lombardi [26] revealed that the perception towards unsafe actions plays a major role when implementing safety measures and that a change in human safety behaviour could have a direct impact on the safety performance of workers. Over the years, different accident causation models have been developed to identify and analyse the impact of unsafe acts and hazards with the ultimate goal of improving safety management and procedures [27]. However, despite the safety measures and procedures currently embedded in the industry, workers still fail to perform tasks safely, therefore, by resolving human error, accidents and fatalities statistics are expected to decrease [28]. 
Human error, also known as human failure, is defined as "an inappropriate human decision or behaviour that reduces either quality or safety (or both) during construction operations and thus deteriorates a project's cost and schedule performance" $[29$, p.826]. Human failure can be categorised into two main types which are active failures and latent failures [30]. Active failures can be expressed as errors having immediate adverse effect on health and safety measures [31]. The three main types of active errors are slips and lapses, mistakes and violations. Slips and lapses are errors made by experienced workers as a result of work familiarity making it easier to be mentally distracted, whereas mistakes are decision-making failures believed to be correct at the time, usually occurring due to a lack of knowledge, stress and tiredness $[\underline{28}, \underline{29}]$. On the other hand, violations are considered to be deliberate nonconformities from safety rules, usually occurring as a result of taking the easy option, time-pressure, overconfidence, work overload, peer-pressure or workers thinking that rules are not applied to them [28]. Latent failures are those aspects of an organisation that indirectly cause accidents and in turn impact on human error and make active failures more likely [32]. Reason [33] described latent failures as actions where damaging consequences may lie dormant until combined with a triggering factor such as active failures Zid et al. [4] refers to latent failures as errors in the safety procedures systems which are associated with a lack of communication between employees and management, uncertainties about rights and responsibilities and time-pressure to meet deadlines faster.

Upon analysing various studies, it becomes apparent that there is a strong relationship between human error when working at heights and safety measures, indicating that further research is necessary. Although Zadow et al. [34] put forward the importance of analysing the psychological state of workers, its impact and influence on 
human error and safety measures when working at heights is yet to be explored in depth within the industry. Therefore, it is crucial for stakeholders to understand the underlying mental processes that lead to an error in order to implement the most appropriate safety measures to reduce fatalities when working at heights.

\subsection{Psychological Distress of Workers}

While the main purpose of the research is to examine the relationship between safety measures and human error, this paper considers a gap in research regarding the influence of the psychological state of workers when working at heights on human error and safety. Numerous studies have tried to blame accident causation solely on human or/and management factors, however, this study argues that the mental state of workers plays a major role on human error occurrences and safety measures [7,24]. Wu et al. [35] outlined that the mental state of workers is directly proportional to their behaviour and safety. Additionally, Mohammadi, Tavakolan, and Khosravi [23] stipulated that the stable emotional state of workers is essential to ensure the work efficiency and safety on site. However, there is limited research into how these factors impact people working at heights.

Psychological distress can be defined as an unconstructive feeling or emotion that influence someone's performance level [35]. Also described as a mental discomfort that interferes with daily activities, a psychological distress is labelled as one of the main reasons for fatalities and injuries on construction sites [23]. According to Enshassi, El-Rayyes, and Alkilani [36], emotional behaviour, which is strongly interconnected with stress, plays a key role in influencing psychological distress among workers working within hazardous environments, resulting in poor safety performance. Moreover, Panuwatwanich, Al-Haadir, and Stewart [37] and Wu et al. [35] indicated that psychological distress is highly related to workers having a risk-taking mindset, 
which leads to inclination to underestimate risks thus choosing not to wear their PPE, being overconfident as well as taking shortcuts to complete tasks, and ultimately resulting in negative impacts on safety measures. According to Kalteh et al. [료], work pressure is one of the main factors influencing safety climate within the construction industry. Work overload and high pressure to meet deadlines can also lead to workers experiencing psychological distress in construction [36]. Additionally, a study by Mohammadi, Tavakolan, and Khosravi [23] concluded that exceeding labours' working capacity can result in them performing the tasks dangerously.

With 7\% of construction workers suffering from clinical depression and stress every year in Australia, costing more than 14.8 billion dollars, the psychological health of workers should be as equally important as organisational productivity needs [39]. Therefore, it is crucial to explore the relationship between all three latent variables outlined in Figure 2.1 in order to determine the most appropriate approaches to decrease human error and improve safety culture while working at heights.

\subsection{Hypotheses Development}

This section describes a hypothetical model that is developed based on the outcome of the theoretical foundation as illustrated in Figure 2.1. It is to better understand the relationship between safety measures and human error while outlining the impact of psychological distress of workers when working at heights. The model would serve as the theoretical foundation for the subsequent questionnaire survey and data analysis.

Hypothesis $1\left(\boldsymbol{H}_{1}\right)=$ Safety measures have a positive impact on psychological distress that can influence the occurrence of accidents when working at heights.

Hypothesis $2\left(\boldsymbol{H}_{2}\right)=$ Psychological Distress have a significant influence on human error impacting on the occurrence of accidents when working at heights. 
Hypothesis $3\left(\boldsymbol{H}_{3}\right)=$ Safety measures have an inverse impact on human error occurrences when working at heights.

\section{Latent Constructs}

$\mathbf{P}=$ Psychological Distress

$\mathbf{P}_{1}=$ Emotional Behaviour (Stress)

$\mathbf{P}_{2}=$ Distractions (Preoccupations)

$\mathbf{P}_{3}=$ High Risk Mindsets (Overconfidence, easy option route and thinking that rules are not applied to them)

$\mathbf{P}_{4}=$ Workload (Overworked and time pressure)

$\mathbf{E}=$ Human Error

$\mathbf{E}_{1}=$ Mistakes

$\mathbf{E}_{2}=$ Slips and Lapses

$\mathbf{E}_{\mathbf{3}}=$ Violations

$\mathbf{S}=$ Safety Measures

$\mathbf{S}_{\mathbf{1}}=$ Sufficient time to complete tasks safely

$\mathbf{S}_{\mathbf{2}}=$ Ability to make suggestions

$\mathbf{S}_{\mathbf{3}}=$ Regular communication between management and employees

$\mathbf{S}_{\mathbf{4}}=$ Safety importance in relation to productivity 
$\mathbf{S} \mathbf{5}=$ Certainty about role and responsibilities

\section{Research Methodology}

\subsection{Scope of Chapter}

The following chapter puts forward the methodology, research sample and data collection followed throughout this paper. This section also looks into the instrument used for data collection and outlines the data analysis strategy.

\subsection{Methodology}

In order to establish the basis for the research and get an overall understanding of the relationship between safety measures and human error and outline the gap when working at heights, a comprehensive theoretical foundation was carried out. In doing so, online databases including Scopus, the Curtin University Online Library and Google Scholar were used to find related published papers on FFH, human error and safety measures embedded in the construction industry. The primary search comprised simple keywords such as human error, falls from heights, safety measures, construction industry, personal protective equipment, occupational fatalities and all-related injuries which lead up to a more detailed search involving keywords such as root cause of construction injuries, falls mortality rates, active and latent human error, injury severity of falls, factors influencing risks of falls, psychological safety climate, emotional/mental state of workers, psychological distress and framework to improve safety behaviour. Through studying relevant research papers, the theoretical foundation in Chapter 2 was formulated leading to the development of hypotheses influencing the relationship between human error and safety measures. 
With the latent constructs identified, a quantitative method approach, through the use of a questionnaire, was selected to collect numerical data to aid in explaining the interrelationship between the latent variables and discuss the most appropriate approach to improve safety [40]. This method was deemed to be the most appropriate as it allowed collected responses to be converted into statistics, which were used to determine whether each hypothesis was accepted or rejected, thus aiding in identifying the relationship between the latent variables and develop a pattern in this research [41]. The questionnaire was designed on a secure online platform that allowed for easy distribution and collection of data. In order to ensure the success and relevancy of the survey within the industry, a pilot questionnaire was provided to 7 randomly selected workers currently working within the Australian construction industry that had experience working at heights. This pilot questionnaire allowed feedback on the questions and structure of the survey to be considered, whereby suggestions have been taken into account when designing the final questionnaire survey, ensuring its validity and reliability [42].

Prior to the distribution of the online survey, both the pilot and final questionnaires were submitted to the Curtin University Research Ethics Board for approval. Once the approval was granted, the questionnaire link and an introductory letter including the research background, objectives and researcher's contact details were spread via email, social media and delivered in-hand, encouraging workers working at heights to participate in the survey while providing opportunity to seek for more information from the researcher if required. By clicking on the provided link, the respondents had direct access to the introductory letter and survey. The primary question, which required respondents to agree to the terms and conditions of taking part in the study, was followed by four questions to collect demographic information that 
described the participants. The remaining questions related to the study were divided into two sections requiring the participants to rate a series of factors outlined in the theoretical foundation associated with the three latent variables. Qualtrics was selected as the online platform chosen to create and distribute the questionnaire and enable submission of surveys to occur smoothly. Once the response period for the survey was completed, all the responses were exported from Qualtrics and uploaded onto IBM SPSS version 24.0 to test the hypothesis. The data analysis method is outlined in Section 3.5.

\subsection{Instrumentation}

Qualtrics, created in 2002, allows data to be securely stored and distributed [44]. Known for its straightforward interface, Qualtrics enables effortless and effective questionnaire creation by providing the required customisation tools to meet the research requirements while ensuring that participants remain anonymous. In addition, the free online platform provides a variety of rating tools with different amendable scales enabling flexibility depending on questions and thus allowing for accurate interpretation of each question [44]. The chosen rating selected for the questionnaire was a 7-point agreement scale ranging from strongly disagree (1), somewhat disagree (2), disagree (3), neither agree nor disagree (4), somewhat agree (5), agree (6) to strongly agree (7), where each rating was assigned with a numerical value for data analysis. In doing so, the software aided in records to be instantaneously converted into Comma Separated Values (CSV) format which has been used to separate and convert responses therefore facilitating data analysis on IBM SPSS version 24.0 and AMOS version 24.0. Recognised as a powerful structural equation modelling software, AMOS version 24.0 was used to investigate the hypothetical inter-relationship between latent variables and latent constructs and the relationship between the variables [44]. 


\subsection{Research Sample and Data Collection}

This study utilised purposive sampling to access its sample population of construction workers within Australian territories who are currently working, or have experience working at heights. This method involved the identification and selection of participants based on knowledge, experience and their ability to communicate and express their opinions, but this method also takes into consideration the availability and willingness of participants [43]. Purposive sampling was selected as it allows researchers to concentrate on participants with specific characteristics - in this instance, participants having experience working at heights - which aids in increasing the research accuracy and relevancy while speeding the data collection process [43]. Through this method, 60 survey responses were collected for analysis.

\subsection{Data Analysis Method}

\subsubsection{Exploratory Factor Analysis (EFA)}

The first statistical technique performed as part of data analysis was an Exploratory Factor Analysis. This technique was deemed most suitable for this study in order to check the appropriateness of the proposed grouping, ascertain the factor structure scale outlined in the hypotheses development and test its reliability [44]. Carried out using the IBM SPSS Statistics software version 24.0, a VARIMAX rotation was performed to determine the degree of contribution of each latent construct to each latent variable $[\underline{45}, \underline{46}]$. According to Seo et al. [45], in order to undertake an EFA, it is imperative for the subjects-to-variables (STV) ratio to be five or greater and with a total of 12 latent constructs, a minimum of 60 survey responses were required. Once the EFA VARIMAX rotation was completed, a Confirmatory Factor Analysis (CFA) was undertaken to establish the confidence in the posited relations between the latent 
variable and the associated latent constructs [44].

\subsubsection{Structural Equation Modelling (SEM)}

Once the measurement model tested and variable grouping was confirmed using the EFA and CFA techniques, AMOS version 24.0 software was utilised to undertake the Structural Equation Modelling (SEM). Considered as a reliable tool and widely used in construction studies, this statistical technique has been chosen to investigate the hypothetical inter-relationship between each latent variable and their latent constructs and the relationship between the three variables in the hypothesised model [44]. The bootstrapping analysis method was adopted to test the significance of the path coefficients and the hypothetical relationships predetermined from the EFA and CFA analysis [47]. The outcome was used to explain the relationship between the three latent variables in order to discuss the most appropriate measures to improve safety and decrease human error when working at heights.

\section{Findings}

\subsection{Scope of Chapter}

This chapter explores the results of the 60 surveys received during the data collection period and the findings of the statistical analysis described in the previous section. The first section outlines the demographic profile of participants while the latter sections discuss the statistical data extracted from the questionnaire results. In the process, this section will also discuss the validity of the results.

\subsection{Demographic Profile and Statistics}

Conducted from August to September 2019, a total of 60 surveys were collected from 
construction workers using the purposive sampling method. Based on the STV ratio outlined by Seo et al. [45], the number of participants have been deemed sufficient for this study based on the number of variables. The participants' demographic profile has been summarised in Table 4.1. The highest proportion of respondents who took part in the survey were between the ages of 35 to 44 years old (26.7\%) followed by participants between the ages of 55 to 64 years old (21.7\%). In terms of experience level, the largest percentage of participants had more than 10 years of experience $(36.7 \%)$. In regard to

which sector of construction respondents had experience in, the most common response was within the commercial sector (31.7\%). When asked about frequency of working on heights, the largest percentage of participants reported working at heights daily (30\%).

\subsection{Explanatory Factor Analysis (EFA)}

As 12 variables were assessed within this study, a sample size of 60 respondents was deemed adequate to accurately complete an EFA [45]. The Shapiro-Wilk normality test was selected to check the data suitability for an EFA where two calibration tests were undertaken which are the Bartlett test of Sphericity $(<0.05)$ and the Kaiser-MeyerOlkin $(\mathrm{KMO})(>0.5)[\underline{46}, \underline{48}]$. The KMO value recorded for the study was 0.759 , which signified a high degree of common variance. Additionally, a large Chi-Square of 456.97 and a $p$ of 0.00 recorded from the Bartlett test of Sphericity, confirmed a significant correlation between the latent constructs which allowed the use of the EFA technique [48].

The factor loading values under a pattern matrix was undertaken to check the appropriateness of the proposed grouping outlined in the hypotheses development and identify if data reduction was required. As illustrated in Table 4.2, the Principle Component Analysis (PCA) technique was adopted as part of the EFA using the Promax rotation method with Kaiser Normalisation. All latent constructs exceeded the 
factor loadings cut-off point of 0.5 recommended by Comrey and Lee [49], therefore excluding the need for factor reduction. However, due to its higher correlation to the 'human error' variable, the 'high-risk-mindset' construct has been regrouped from the 'psychological distress' variable as originally proposed under Chapter 2.

\subsection{Confirmatory Factor Analysis}

The CFA statistical technique was carried out after the EFA grouping was completed to test if the data fitted the new model. To ensure reliability, the Cronbach's Alpha, Average Variance Extracted (AVE) and Composite Reliability (CR) values have been calculated and summarised within Table 4.3. The Cronbach's Alpha values ranged between 0.811 and 0.908 , exceeding the minimum threshold of 0.7 suggested by Nunnally [이. Similarly, the AVE values ranged between 0.623 and 0.716 , exceeding the minimum threshold of 0.5 recommended by Liu, Zhao, and Li [46], while the CR values ranged between 0.843 and 0.926 , surpassing the minimum threshold of 0.7 outlined by Raykov [51]. As the results confirmed the relatability and validity of the new measurement models, the structural path modelling is permissible [46].

\section{Structural Equation Modelling (SEM)}

Based on the hypotheses developed in Chapter 2 and the EFA results, a bootstrapping technique was adopted to estimate the path coefficients' significance and test the 3 hypotheses. The bootstrap sample used for this study is 5000 as suggested by Hair, Ringle, and Sarstedt [47] using the 60 survey responses as the number of cases. Identified as a two-tailed test, in order to assess the significance of the original sample, the critical t-values recommended are the $1.65,1.96$ or the $2.58 \mathrm{t}$-values which each have a significance level of $10 \%, 5 \%$ and $1 \%$ respectively [47]. Interpreted within Table 4.5, the results showed a significant positive path coefficient for $H_{2}$ and $H_{3}$ and a 
negative path coefficient for $H_{1}$. In order to more accurately demonstrate the findings, a new hypotheses model is expressed in Figure 4.1.

In summary, the model demonstrates a significant direct relationship between 'psychological distress' and 'human error' and 'safety measures' and 'human error'. However, the model also demonstrates a strong inverse relationship between 'safety measures' and 'psychological distress'.

\section{Discussion}

\subsection{Scope of Chapter}

In this section, an exploration of each of the 3 latent variables in regard to their relationship and significance with the other latent variables assessed in Chapter 4 is outlined. The variables in relation to both the analysis of survey responses and the theoretical foundation was considered to increase the accuracy of the discussion. Lastly, this chapter discusses the most appropriate preventative measures to improve safety while working at heights.

\subsection{Hypotheses}

As outlined within the theoretical foundation, numerous researchers have focused on the implementation of physical safety measures to decrease the occurrence of accidents and hazards. However, little research had been conducted on the relationship between safety measures and psychological distress and how it impacts on occurrence of accidents $[\underline{4}, \underline{8}, \underline{10}, \underline{22}]$. When analysing the relationship between safety measures and psychological distress, $H_{l}$ has a high negative significance of 5\%. The hypothesis developed in Chapter 2 predicted that safety measures have a positive impact on psychological distress that can influence the occurrence of accidents when working at 
heights. According to Freeman and Young [52], a negative correlation coefficient signifies an inverse relationship between the latent variables. Therefore, when considering the research findings, safety measures are indirectly proportional to psychological distress, meaning that an increase in safety measures could drastically decrease psychological distress, confirming the hypothesis. This study stresses the importance of investing the benefits of psychological safety measures as opposed to solely focusing on physical safety measures to improve safety.

As discussed in Chapter 2, numerous studies have tried to blame accident causation solely on human error, however, limited research has analysed the possible impact of mental health on human error which may ultimately leads to accidents within the industry. $[\underline{7,24]}$. When exploring the relationship between psychological distress and human error, the results of $H_{2}$ showed a high positive significance of $1 \%$. The $H_{2}$, based on the theoretical foundation, predicted that psychological distress has a significant influence on human error impacting on the occurrence of accidents when working at heights. Established in Chapter 4, psychological distress was discovered to be proportional to human error, confirming its direct relationship, meaning that an increase in psychological distress also increases the occurrence of human error. Thoroughly researched within the health sector, the findings of this study are in line with the theory developed by Reason [33], outlining that human error can arise from mental distress associated with the professional and personal lives of nurses, surgeons and physicians. However, limited studies have addressed this relationship within a hazardous working environment similar to the construction industry. This study fills an important gap by finding that psychological distress is a driver of human error and occupational accidents in the construction industry. 
Lastly, as aforementioned within the theoretical foundation, several researchers have concluded that safety measures are indirectly proportional to human error that is an increase in safety measures would decrease human error $[\underline{14}, \underline{22}, \underline{23}, \underline{53}]$. Thus, $H_{3}$ was developed predicting that safety measures have an inverse impact on human error occurrences when working at heights. As described in Chapter 2, safety measures have been assessed based on current ongoing issues within the industry and limited research in terms of regular communication, safety importance awareness, rights and responsibilities and having enough time to complete tasks safely. However, when looking into the relationship between safety measures and human error, the results of $\mathrm{H}_{3}$ showed a high positive significance of $5 \%$, contradicting the statement outlined in the hypotheses development. As a result, the research showed a direct relationship between the two latent variables that is an increase in safety measures does not decrease human error as concluded in Chapter 2. In conclusion, the results found a strong relationship between the three variables whereby improving safety measures could decrease psychological distress which can in turn decrease human error.

\subsection{Preventative Measures}

Consequently, based on the relationship between each of the 3 latent variables, the study established that psychological distress is a driver of human error and accident causation and that proper implementation of psychological safety measures could decrease the occurrence of human failures and accidents within the construction industry. The basic premise of this paper was to understand whether human failure is expected as a result of psychological distress and therefore, it is imperative to implement countermeasures. Despite being relatively impossible to change human behaviour, it is possible however to implement appropriate approaches to detect and reduce psychological distress of workers, in order to improve safety and decrease accident causations. 
In order for the appropriate approaches to be implemented when working at heights, it is vital to look into some successful models developed within the health sector. Michie [54] developed a framework which is widely used to combat against psychological distress and reduce human error, outlining that it is imperative for institutions to implement both individual and organisational approaches to reduce psychological distress risks. Reason's [3] research found that focusing on psychological training is the most efficient individual approach to change the workers' skills and views on psychological distress. Psychological training allows workers to learn how to become aware of psychological distress signs and behaviour patterns, allowing them to implement coping skills techniques such as thinking positively, relaxation and breathing. However, despite this approach being successful in nonhazardous environments, Michie [54] categorised this method as providing a temporary feeling of well-being rather than eliminating the damaging situation. Therefore, in order to maximise the effectiveness of individual approach and the implementation of psychological training, developing services in terms of counselling and frequent psychological assessment is expected to reduce human error and psychological distress and improve safety when working at heights. In order to ensure the effectiveness of this approach, the questionnaire assessed the number of respondents willing to undergo psychological assessment whereby $28.33 \%$ of respondents strongly agreed and $43.33 \%$ agreed that they would be willing to undertake a psychological assessment to reduce human error and improve safety, confirming the readiness of this approach within workers working at heights in the construction industry.

Additionally, implementing new organisational approaches are expected to decrease psychological stress within workplaces [33]. One of the most efficient approaches studied within the health sector is through the implementation of new 
technologies which significantly allowed for the reduction of psychological distress through continuous monitoring of mental state [54]. Electroencephalography (EEG) is one of the most reliable and non-invasive wearable device frequently used in clinical diagnostic tests to measure brain activity such as emotional behaviours, mental fatigue and distraction which are then converted into symptom description [55]. To advance the use of this technology in the construction industry outside of lab settings, a mobile device has been altered and integrated in hardhats to allow continuous monitoring of workforce's mental state [56]. Therefore, one viable option to increase psychological safety measures in the construction industry, which may in turn decrease human error, is through the implementation of an EEG device and continuous monitoring which can be used to aid the management of psychological distress and thus decrease human error in the industry.

\section{Conclusion and Further Research}

Over the past few years, several researches and literature reviews on construction safety and human error have been conducted expanding different measures and approaches to decrease the occurrence of organisational and physical hazards. However, despite these approaches having a positive impact in reducing the number of fatalities, FFH is still recorded with having the highest rates among construction accidents compared to other types of accidents in the industry [14]. As a result, this study aimed to analyse the relationship between human error and safety measures from a different perspective by investigating the impact of psychological distress in order to contribute towards accidents minimisation when working at heights. The study revealed that safety measures is inversely proportional to psychological distress whereas human error is proportional to safety measures and psychological distress, demonstrating contrasting results from previous researches which state that increasing physical safety measures 
decreases human error. However, this research indicates that increasing safety measures could decrease psychological distress and as a result decrease human error when working at heights. Thoroughly explored within the health sector, it was discovered that human error is an interdisciplinary area of psychology, which impacts workplace safety, supporting the study's results that psychological distress is a driver of human error and occupational accidents in the construction industry [13]. Through this discovery, the study concludes by providing relevant organisational and individual approaches to combat against psychological distress and reduce human error when working at heights. Therefore, the practical implication that can be drawn from this study for safety measures, psychological distress and human error, is that a proper understanding of the impact of psychological distress on safety measures and on the occurrence of human error when working at heights could allow for organisations to implement the most effective and suitable preventative measures and develop new policies to decrease the occurrence of accidents in the construction industry.

However, this area of research still has scope for further exploration. Future studies should analyse other aspects of psychological distress such as depression and anxiety. A recent research conducted by Mirza et al. [57] found that depression and anxiety influence safety climate among workers and it is imperative to analyse its effects on safety measures and human error. Additionally, while the study outlines some preventative measures that have been tested and implemented within the health industry, another recommendation for future studies would be to test the different approaches within the construction industry when working at heights with the goal to identify the impact of such implementation on cost, productivity and privacy of workers. 
The study significantly contributes to the body of knowledge not only by outlining the relationship between safety measures and human error but also by exploring the effects of psychological distress on accident causations when working at heights in the construction industry. Thus, this study is the first that analyses the interconnection between human error, safety measures and psychological distress, providing evidence that can be useful to reduce the number of fatalities in the construction industry.

\section{Disclosure Statement}

There has been no conflict of interest reported by the author.

\section{References}

1. Jahangiri M, Solukloei HRJ, Kamalinia M. A neuro-fuzzy risk prediction methodology for falling from scaffold. Safety science. 2019;117:88-99.

2. SafetySolutions.net.au[Internet]. Australia: Safety Solution; [cited 2018 June 27]. Available from:

https://www.safetysolutions.net.au/content/height/article/10-falls-from-heightstatistics-you-need-to-know-1118932781

3. Hinze J, Pedersen C, Fredley J. Identifying root causes of construction injuries. Journal of Construction Engineering and Management. 1998;124(1):67-71.

4. Zid C, Kasim N, Benseghir H, et al., editors. Developing an Effective Conceptual Framework for Safety Behaviour in Construction Industry. E3S Web of Conferences; 2018: EDP Sciences.

5. SafetyandHealthMagazine.com[Internet]. Australia: National Safety Council; [cited 2018 Jan 30]. Available from: https://www.safetyandhealthmagazine.com/articles/16646-percentofconstruction-worker-deaths-involve-falls-new-database-shows

6. Thevendran V, Mawdesley M. Perception of human risk factors in construction projects: an exploratory study. International journal of project management. 2004;22(2):131-137.

7. Teo EAL, Ling FYY, Chong AFW. Framework for project managers to manage construction safety. International Journal of project management. 2005;23(4):329-341.

8. Adam JM, Pallarés FJ, Calderón PA. Falls from height during the floor slab formwork of buildings: current situation in Spain. Journal of safety research. 2009;40(4):293-299.

9. Liang H, Zhang S. Impact of supervisors' safety violations on an individual worker within a construction crew. Safety Science. 2019;120:679-691.

10. Gomez-de-Gabriel JM, Fernández-Madrigal JA, Lopez-Arquillos A, et al. Monitoring harness use in construction with BLE beacons. Measurement. 2019;131:329-340. 
11. Zhang S, Sulankivi K, Kiviniemi M, et al. BIM-based fall hazard identification and prevention in construction safety planning. Safety science. 2015;72:31-45.

12. Legislation FR. Work Health and Safety Act 2011 (WHS) Australia2011.

13. Furukawa TA, Kessler RC, Slade T, et al. The performance of the K6 and K10 screening scales for psychological distress in the Australian National Survey of Mental Health and Well-Being. Psychological medicine. 2003;33(2):357-362.

14. Nadhim E, Hon C, Xia B, et al. Falls from height in the construction industry: a critical review of the scientific literature. International journal of environmental research and public health. 2016;13(7):638.

15. SafeWork.nsw.gov.au[Internet]. Australia (NSW): SafeWork NSW; [cited 2016]. Available from: https://www.safework.nsw.gov.au/legalobligations/employer-business-obligations/managing-hazards-and-risks

16. SafeWorkAustralia.gov.au[Internet]. Australia: Safe Work Australia; [cited 2015 Dec 31]. Available from: https://www.safeworkaustralia.gov.au/heights

17. Gillen M, Faucett JA, Beaumont JJ, et al. Injury severity associated with nonfatal construction falls. American Journal of Industrial Medicine. 1997;32(6):647-655.

18. Zerguine H, Tamrin SBM, Jalaludin J. Prevalence, source and severity of workrelated injuries among "foreign" construction workers in a large Malaysian organisation: a cross-sectional study. Industrial health. 2018:264-273.

19. Alizadehsalehi S, Yitmen I, Celik T, et al. The effectiveness of an integrated $\mathrm{BIM} / \mathrm{UAV}$ model in managing safety on construction sites. International journal of occupational safety and ergonomics. 2018:1-16.

20. Brodskiy V, editor Parameters of the safety and fall arrest nets in buildings under construction. E3S Web of Conferences; 2019: EDP Sciences.

21. Bejinariu C, Burduhos-Nergiş D-P, Cimpoeşu N, et al. Study on the anticorrosive phosphated steel carabiners used at personal protective equipment. Calitatea. 2019;20(S1):71.

22. Kaskutas V, Dale AM, Lipscomb H, et al. Fall prevention and safety communication training for foremen: Report of a pilot project designed to improve residential construction safety. Journal of safety research. 2013;44:111118.

23. Mohammadi A, Tavakolan M, Khosravi Y. Factors influencing safety performance on construction projects: A review. Safety science. 2018;109:382397.

24. Hallowell MR, Yugar-Arias IF. Exploring fundamental causes of safety challenges faced by Hispanic construction workers in the US using photovoice. Safety science. 2016;82:199-211.

25. Korkmaz S, Park DJ. The effect of safety communication network characteristics on safety awareness and behavior in a liquefied natural gas terminal. International Journal of Occupational Safety and Ergonomics. 2019:116.

26. Fargnoli M, Lombardi M. Preliminary Human Safety Assessment (PHSA) for the Improvement of the Behavioral Aspects of Safety Climate in the Construction Industry. Buildings. 2019;9(3):69.

27. Ohsbok.org.au[Internet]. Australia (VIC): Safety Institute of Australia Ltd; [cited 2012]. Available from: http://www.ohsbok.org.au/wpcontent/uploads/2013/12/32-Models-of-causation-Safety.pdf 
28. Ye G, Tan Q, Gong X, et al. Improved HFACS on Human Factors of Construction Accidents: A China Perspective. Advances in Civil Engineering. 2018;2018:1-15.

29. Chi S, Han S, Kim DY. Relationship between unsafe working conditions and workers' behavior and impact of working conditions on injury severity in US construction industry. Journal of Construction Engineering and Management. 2012;139(7):826-838.

30. HSE.gov.uk[Internet]. United Kingdom: Health and Safety Executive; [cited 2019]. Available from: http://www.hse.gov.uk/humanfactors/topics/humanfail.htm

31. Chiu M-C, Hsieh M-C. Latent human error analysis and efficient improvement strategies by fuzzy TOPSIS in aviation maintenance tasks. Applied ergonomics. 2016;54:136-147.

32. NOPSEMA.gov.au[Internet]. Australia: NOPSEMA; [cited 2018]. Available from: https://www.nopsema.gov.au/resources/human-factors/human-error/

33. Reason J. The contribution of latent human failures to the breakdown of complex systems. Philosophical Transactions of the Royal Society of London B, Biological Sciences. 1990;327(1241):475-484.

34. Zadow AJ, Dollard MF, Mclinton SS, et al. Psychosocial safety climate, emotional exhaustion, and work injuries in healthcare workplaces. Stress and Health. 2017;33(5):558-569.

35. Wu X, Liu Q, Zhang L, et al. Prospective safety performance evaluation on construction sites. Accident Analysis \& Prevention. 2015;78:58-72.

36. Enshassi A, El-Rayyes Y, Alkilani S. Job stress, job burnout and safety performance in the Palestinian construction industry. Journal of Financial Management of Property and Construction. 2015;20(2):170-187.

37. Panuwatwanich K, Al-Haadir S, Stewart RA. Influence of safety motivation and climate on safety behaviour and outcomes: evidence from the Saudi Arabian construction industry. International journal of occupational safety and ergonomics. 2017;23(1):60-75.

38. Kalteh HO, Mortazavi SB, Mohammadi E, et al. The relationship between safety culture and safety climate and safety performance: a systematic review. International journal of occupational safety and ergonomics. 2019:1-11.

39. Idris MA, Dollard MF, Coward J, et al. Psychosocial safety climate: Conceptual distinctiveness and effect on job demands and worker psychological health. Safety science. 2012;50(1):19-28.

40. Sogunro OA. Selecting a quantitative or qualitative research methodology: An experience. Educational Research Quarterly. 2002;26(1):3.

41. Newman I, Benz CR, Ridenour CS. Qualitative-quantitative research methodology: Exploring the interactive continuum. SIU Press; 1998.

42. Van Teijlingen ER, Hundley V. The importance of pilot studies. 2001;16(40):33-36.

43. Etikan I, Musa SA, Alkassim RS. Comparison of convenience sampling and purposive sampling. American journal of theoretical and applied statistics. 2016;5(1):1-4.

44. Chinda T, Mohamed S. Structural equation model of construction safety culture. Engineering, Construction and Architectural Management. 2008;15(2):114-131.

45. Seo D-C, Torabi MR, Blair EH, et al. A cross-validation of safety climate scale using confirmatory factor analytic approach. Journal of safety research. 2004;35(4):427-445. 
46. Liu J, Zhao X, Li Y. Exploring the factors inducing contractors' unethical behavior: case of China. Journal of Professional Issues in Engineering Education and Practice. 2016;143(3):04016023.

47. Hair JF, Ringle CM, Sarstedt M. PLS-SEM: Indeed a silver bullet. Journal of Marketing theory and Practice. 2011;19(2):139-152.

48. Zahoor H, Chan A, Utama W, et al. Modeling the relationship between safety climate and safety performance in a developing construction industry: a crosscultural validation study. International journal of environmental research and public health. 2017;14(4):351.

49. Comrey AL, Lee HB. A first course in factor analysis. Psychology press; 2013.

50. Nunnally JC. Psychometric theory-25 years ago and now. Educational Researcher. 1975;4(10):7-21.

51. Raykov T. Coefficient alpha and composite reliability with interrelated nonhomogeneous items. Applied psychological measurement. 1998;22(4):375385.

52. Freeman J, Young T. Correlation coefficient: association between two continuous variables. Scope Tutorials. 2009:1-3.

53. Zohar D. Thirty years of safety climate research: Reflections and future directions. Accident Analysis \& Prevention. 2010;42(5):1517-1522.

54. Michie S. Causes and management of stress at work. Occupational and environmental medicine. 2002;59(1):67-72.

55. Xu X, Gu H, Yan S, et al. Fatigue EEG Feature Extraction Based on Tasks with Different Physiological States for Ubiquitous Edge Computing. IEEE Access. 2019;7:73057-73064.

56. Acar G, Ozturk O, Golparvar AJ, et al. Wearable and Flexible Textile Electrodes for Biopotential Signal Monitoring: A review. Electronics. 2019;8(5):479.

57. Mirza MZ, Isha ASN, Memon MA, et al. Psychosocial safety climate, safety compliance and safety participation: The mediating role of psychological distress. Journal of Management \& Organization. 2019:1-16. 
Table 4.1. Participants' Demographic Profile.

\begin{tabular}{|c|c|c|c|}
\hline \multicolumn{2}{|l|}{ Characteristics } & \multirow{2}{*}{$\frac{\mathrm{N}}{12}$} & \multirow{2}{*}{$\frac{\text { Percent }}{20.0}$} \\
\hline Age (Years) & $18-24$ & & \\
\hline & $35-44$ & 16 & 26.7 \\
\hline & $45-54$ & 12 & 20.0 \\
\hline & $55-64$ & 13 & 21.7 \\
\hline & $65-74$ & 6 & 10.0 \\
\hline & $>74$ & 1 & 1.7 \\
\hline & Total & 60 & 100.0 \\
\hline \multirow{7}{*}{$\begin{array}{l}\text { Experience Level } \\
\text { (Years) }\end{array}$} & No Experience & 1 & 1.7 \\
\hline & $<1$ Year & 5 & 8.3 \\
\hline & 1-2 Years & 12 & 20.0 \\
\hline & 3-5 Years & 9 & 15.0 \\
\hline & 6-9 Years & 11 & 18.3 \\
\hline & $10+$ Years & 22 & 36.7 \\
\hline & Total & 60 & 100.0 \\
\hline \multirow[t]{5}{*}{ Education Level } & High School Graduate & 18 & 30.0 \\
\hline & Diploma or Certificate & 29 & 48.3 \\
\hline & Bachelor's degree & 11 & 18.3 \\
\hline & $\begin{array}{l}\text { Master or Doctorate } \\
\text { Degree }\end{array}$ & 2 & 3.3 \\
\hline & Total & 60 & 100.0 \\
\hline \multirow[t]{7}{*}{ Sector } & Residential & 17 & 28.3 \\
\hline & Commercial & 19 & 31.7 \\
\hline & Industrial & 11 & 18.3 \\
\hline & Infrastructure & 5 & 8.3 \\
\hline & Oil and Gas & 4 & 6.7 \\
\hline & Other & 4 & 6.7 \\
\hline & Total & 60 & 100.0 \\
\hline \multirow{6}{*}{$\begin{array}{l}\text { Work Frequency } \\
\text { (At Heights) }\end{array}$} & Daily & 18 & 30.0 \\
\hline & 4-6 times a week & 15 & 25.0 \\
\hline & 2-3 times a week & 12 & 20.0 \\
\hline & Once a week & 11 & 18.3 \\
\hline & Never & 4 & 6.7 \\
\hline & Total & 60 & 100.0 \\
\hline
\end{tabular}


Table 4.2. Pattern Matrix - EFA Results.

\begin{tabular}{lccc}
\hline Latent Constructs & Safety Measures & Human Error & $\begin{array}{c}\text { Psychological } \\
\text { Distress }\end{array}$ \\
\hline Completion-Time & 0.737 & & \\
Voice-Concerns & 0.766 & & \\
Regular-Communication & 0.887 & & \\
Safety-Importance & 0.930 & & \\
Rights/Responsibilities & 0.920 & & 0.958 \\
Emotional-Behaviour & & & 0.694 \\
Distractions & & & 0.859 \\
Workload & & 0.673 & \\
High-Risk-Mindset & & 0.897 & \\
Mistakes & & 0.947 & \\
Slips-and-Lapses & & 0.698 & \\
Violations & & & \\
\hline
\end{tabular}

Extraction Method: Principal Component Analysis.

Rotation Method: Promax with Kaiser Normalization.

a. Rotation converged in 5 iterations.

Table 4.3. Measurement Model Evaluation.

\begin{tabular}{ccccc}
\hline Latent Variables & $\begin{array}{c}\text { Cronbach's } \\
\text { Alpha }\end{array}$ & N of Items & AVE & CR \\
\hline Safety Measures & 0.908 & 5 & 0.716 & 0.926 \\
Human Error & 0.832 & 4 & 0.632 & 0.872 \\
$\begin{array}{c}\text { Psychological } \\
\text { Distress }\end{array}$ & 0.811 & 3 & 0.644 & 0.843 \\
\hline
\end{tabular}


Table 4.4. Path Analysis Results.

\begin{tabular}{lcccccc}
\hline Path & $\begin{array}{c}\text { Original } \\
\text { Sample }\end{array}$ & $\begin{array}{c}\text { Sample } \\
\text { Mean }\end{array}$ & $\begin{array}{c}\text { SD } \\
\text { Error }\end{array}$ & $\begin{array}{c}\mathrm{t}- \\
\text { Value }\end{array}$ & Sig. & Interpretation \\
\hline P.D $\leftarrow$ S.M & -0.341 & -0.317 & 0.134 & -2.407 & -0.05 & Supported \\
H.E $\leftarrow$ P.D & 0.518 & 0.608 & 0.167 & 3.409 & 0.01 & Supported \\
H.E $\leftarrow$ S.M & 0.298 & 0.322 & 0.145 & 2.152 & 0.05 & Supported \\
\hline
\end{tabular}


Figure 2.1. Hypothetical Model.

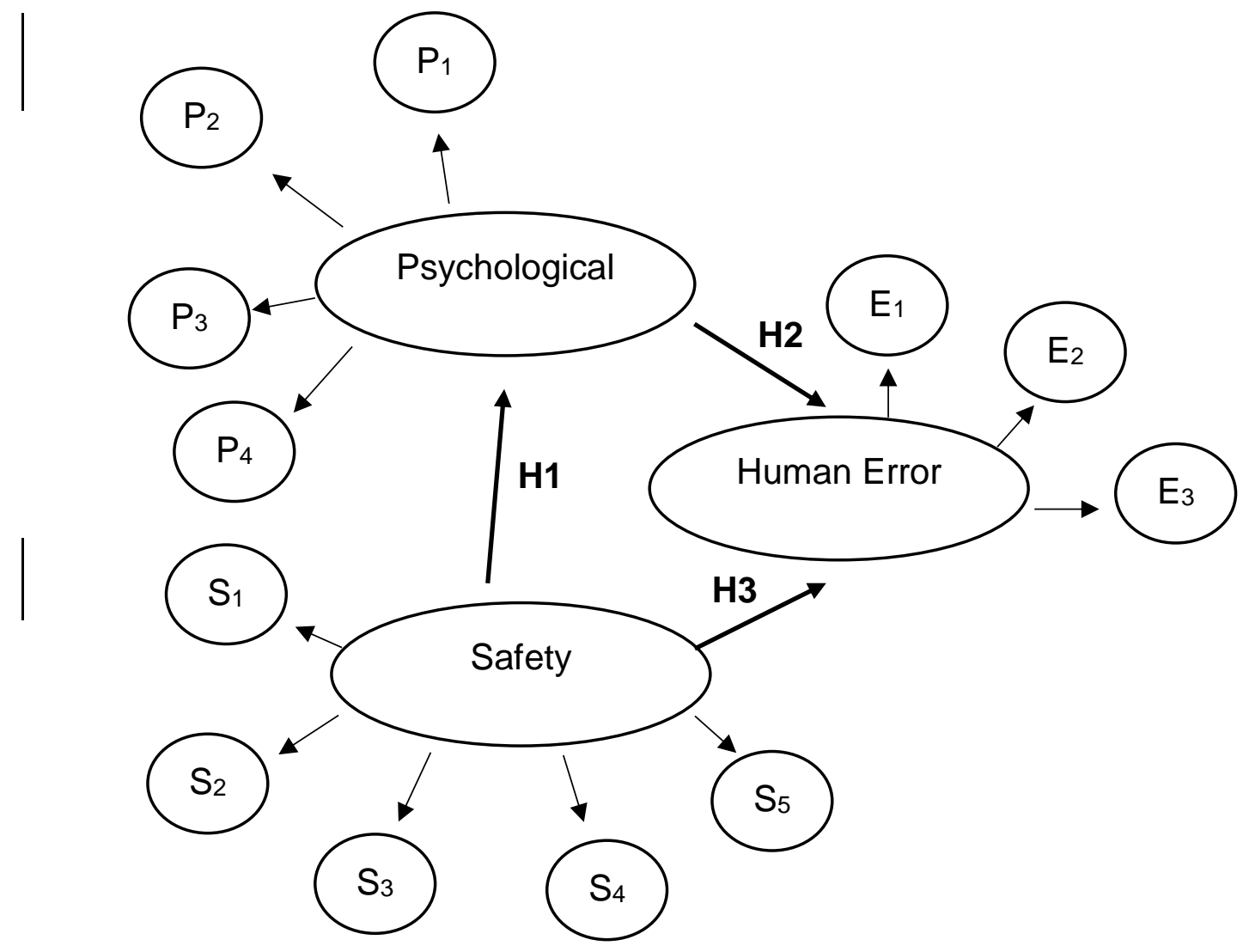


Figure 4.1. Hypotheses Relationship Model.

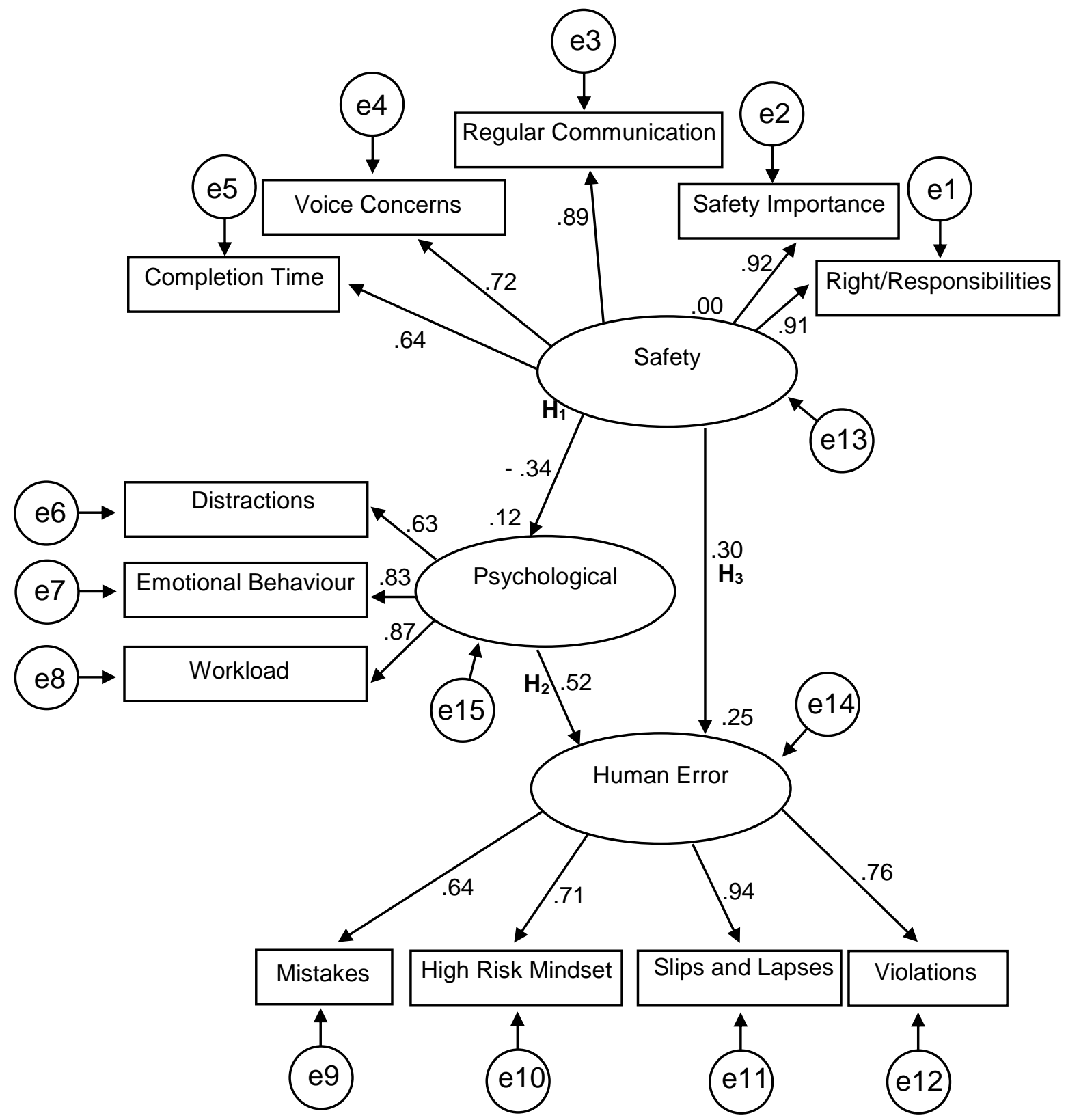

